\title{
Publisher Correction: Get the IL-17F outta here!
}

Aisling O'Hara Hall@i, Jennifer E. Towne and Scott E. Plevy

Correction to: Nature Immunology https://doi.org/10.1038/s41590-018-0141-z (2018), published online 18 June 2018.

In the version of this article initially published, a word ("neutraling") in sentence 2 of paragraph 5 was incorrect. The correct phrase is "...neutralizing properties.... The error has been corrected in the HTML and PDF version of the article.

Published online: 1 February 2019

https://doi.org/10.1038/s41590-019-0332-2

\section{Publisher Correction: c-Maf controls immune responses by regulating disease-specific gene networks and repressing IL-2 in CD4 ${ }^{+} \mathrm{T}$ cells}

Leona Gabryšová(D), Marisol Alvarez-Martinez, Raphaëlle Luisier (iD, Luke S. Cox (D), Jan Sodenkamp, Caroline Hosking, Damián Pérez-Mazliah, Charlotte Whicher, Yashaswini Kannan, Krzysztof Potempa, Xuemei Wu, Leena Bhaw, Hagen Wende, Michael H. Sieweke, Greg Elgar, Mark Wilson, James Briscoe (D), Vicki Metzis (D), Jean Langhorne, Nicholas M. Luscombe (iD) and Anne O'Garra (D)

Correction to: Nature Immunology https://doi.org/10.1038/s41590-018-0083-5 (2018), published online 16 April 2018.

In the version of this article initially published, the Supplementary Data file was an incorrect version. The correct version is now provided. The error has been corrected in the HTML and PDF version of the article.

Published online: 8 February 2019

https://doi.org/10.1038/s41590-019-0331-3

\section{Publisher Correction: Recent progress in broadly neutralizing antibodies to HIV}

Devin Sok (D) and Dennis R. Burton (iD)

Correction to: Nature Immunology https://doi.org/10.1038/s41590-018-0235-7 (2018), published online 17 October 2018.

In the version of this article initially published, some of the references in Table 1 were incorrect. The correct references are as follows: in row 12, refs. 12,44 should be ref. 12; in row 16, refs. 2,17,27 should be ref. 109 (Walker, L. M. et al. Broad neutralization coverage of HIV by multiple highly potent antibodies. Nature 477, 466-470 (2011)); in row 25, refs. 61,76 should be ref. 110 (Wu, X. et al. Rational design of envelope identifies broadly neutralizing human monoclonal antibodies to HIV-1. Science 329, 856-861 (2010)); and in the bottom row, ref. 57 should be ref. 111 (Huang, J. et al. Broad and potent neutralization of HIV-1 by a gp41-specific human antibody. Nature 491, 406-412 (2012)). Those new references (109-111) should be included in the reference list. The errors have been corrected in the HTML and PDF versions of the article. 